\title{
Formação continuada de professores no PAR em municípios do Rio Grande do Norte e Pará
}

\author{
Maria Aparecida de Queiroz \\ Marcos Torres Carneiro \\ Universidade Federal do Rio Grande do Norte \\ Maria Edilene da Silva Ribeiro \\ Universidade Federal do Pará
}

\section{Resumo}

Este artigo analisa aspectos da formação continuada de professores para a melhoria da qualidade do ensino fundamental. É um recorte da pesquisa "Avaliação do Plano de Ações Articuladas (PAR): um estudo em municípios dos estados do Rio Grande do Norte, Pará e Minas Gerais no período de 2007 a 2011 1", OBEDUC/ CAPES e apresenta dados sobre o Rio Grande do Norte e Pará. Coteja: literatura, documentos, descritores dos conceitos, parte de entrevistas realizadas com membros das Secretarias Municipais de Educação envolvidos no PAR, aporte legal e normativo. As entrevistas seguiram o WordSmith Tools, que definiu a Word list e um corpus com mil palavras, concord. Os sujeitos estão identificados pela sigla do estado e do município; ordem dos entrevistados e pergunta. Contempla as categorias: regime de colaboração, participação, parceria e autonomia identificadas como tendências nas relações intergovernamentais. Predominavam relações verticalizadas, a União financiava a política e os demais entes tinham autonomia relativa.

Palavras-chave: Formação continuada de professores. Plano de Ações Articuladas. Relações intergovernamentais.

\section{Continuous formation of teachers in the PAR in municipalities of Rio Grande do Norte and Pará}

\section{Abstract}

This paper analyzes continuous teacher formation aspects to improve the quality of elementary school. This is part of the research "Evaluation of Articulated Actions Plan: a study in municipalities of the states of Rio Grande do Norte, Pará and Minas Gerais in the period between 2007 and 2011 " (Avaliação do Plano de Ações Articuladas (Par): um estudo em municípios dos estados do Rio Grande do Norte, Pará e Minas Gerais no período de 2007 a 201 1), OBEDUC/CAPES and it reports data on Rio Grande do Norte and Pará. It collages from: literature, documents, descriptors of essential concepts, interviews held with members of Municipal Education Departments involved in PAR, and legal and regulatory contribution. The interviews followed the WordSmith Tools, which 
Formação continuada de professores no PAR em municípios do Rio Grande do Norte e Pará

established the Word list and a corpus with a thousand words, the concord. The subjects are identified by the initials of the state and the municipality; order of respondents and question. It includes these categories: collaboration, participation, partnership and autonomy, identified as trends in the intergovernmental relations. Vertical relations prevailed, the Union financed the policy and the other entities had relative autonomy.

Keywords: Continuous formation of teachers. Articulated Actions Plan. Intergovernmental relations.

\section{Formación continuada de profesores en el PAR en municipios del Río Grande del Norte y Pará}

\section{Resumen}

Este artículo analiza aspectos de la formación continuada de profesores para la mejora de la calidad de la enseñanza fundamental. Es un recorte de la investigación "Evaluación del Plan de Acciones Articuladas (PAR): un estudio en municipios de los estados de Rio Grande do Norte, Pará y Minas Gerais en el período de 2007 a 201 1, OBEDUC/CAPES y presenta datos sobre el Río Grande Coteja: literatura, documentos, descriptores de los conceptos, parte de entrevistas realizadas con miembros de las Secretarías Municipales de Educación involucrados en el PAR, aporte legal y normativo. Las entrevistas siguieron a WordSmith Tools, que definió Wordlist y un corpus con mil palabras, concord. Los sujetos están identificados por la sigla del estado y del municipio; Orden de los entrevistados y pregunta. Se contemplan las categorías: régimen de colaboración, participación, asociación y autonomía identificadas como tendencias en las relaciones intergubernamentales. Predomina las relaciones verticales, la Unión financiaba la política y los demás entes tenían autonomía relativa.

Palabras clave: Formación continuada de profesores. Plan de Acción Articulada. Relaciones intergubernamentales.

\section{Introdução}

Nos propósitos deste artigo, analisamos aspectos da formação continuada de professores - dimensão do Plano de Ações Articuladas 2007 a 2011 -, que visava promover a melhoria da qualidade do ensino fundamental, como recorte da pesquisa "Avaliação do Plano de Ações Articuladas (PAR): um estudo em municípios dos estados do Rio Grande do Norte, Pará e Minas Gerais no período de 2007 a 201 1", OBEDUC/CAPES apresenta dados referentes aos estados do Rio Grande do Norte e do Pará. Consideramos, 
portanto, que a contingência de escrever um texto impõe alguns desafios, entre os quais, a escolha de fontes, como a literatura, documentos (planos e relatórios), legislação, dados estatísticos e informações, obtidas por meio de entrevistas - compatíveis com as opções epistemológicas, teóricas, metodológicas e políticas dos autores e com os objetivos da investigação.

Independentemente de as fontes serem escassas ou abundantes, faz-se necessário o rigor na seleção e no uso deles desde a localização, a leitura, a seleção, a organização e a análise. Em se tratando de um tema relativo à política educacional, o artigo conta com aporte e abordagens multifacetadas em torno de sujeitos e de objetos distintos.

A educação formal se baseia em processos históricos que se concretizam, preferencialmente, por meio da escola, como instituição educativa. Em nossa cultura, os processos escolares abarcam o desenvolvimento dos seres humanos, e a escolarização básica compreende a infância e a juventude. Dessa forma, a educação dos filhos dos trabalhadores assalariados, mantida pelo Estado brasileiro, com a Constituição federal de 1988, art. 206, tem como princípio que o lócus onde se desenvolve o ensino carece de "[...] condições para o acesso e permanência na escola" (BRASIL, 1988, p. 10, grifo nosso). Isso implica, portanto, o estudante ser bem-sucedido em aprendizagens distintas relativas aos conhecimentos específicos e àqueles próprios da convivência humana, incluindo-se atitudes e habilidades para lidar com ferramentas modernas das ciências e das tecnologias.

Em artigo sobre a escola, Lima (2008, p. 1) ressalta alguns avanços decorrentes da institucionalização e da generalização da "[...] forma escolar moderna $[\ldots]$ ", considerando-a "[...] um objecto de estudo complexo e polifacetado, construído sob variadas influências teóricas e tradições disciplinares". A escola é, antes de tudo, um espaço vivo de natureza ontológica formado por professores, funcionários, estudantes, com conhecimentos axiológicos - valores, crenças, posturas religiosas, políticas, ideológicas -, entre outros. Nela, se concretiza a educação formal, ou institucionalizada, que é movida por saberes e conhecimentos de natureza distinta, os quais se materializam no ensino por meio da transposição didática. $\bigcirc$ espaço institucional é também definido por leis, normas e regras, de onde emanam e para onde confluem conflitos e consensos. 
Desse modo, o conhecimento veiculado no espaço escolar, por meio de práticas pedagógicas, culturais, artísticas, desportivas e religiosas, nem sempre é compatível com os aspectos da vida que transcendem os ditames das políticas de educação, em particular o currículo formal. Sob esse ângulo, para que a instituição se associe às expectativas dos estudantes, de suas famílias e da sociedade, é necessário que se ponha em evidência um currículo adequado aos estudantes como sujeitos da história. Essa perspectiva de politização pressupõe conhecer, discutir, compreender e transformar a realidade.

Diferentemente dessa perspectiva, quando se cuida, preferencialmente, da enculturação, inviabiliza-se a superação dos conflitos decorrentes das assimetrias próprias da convivência humana nos espaços onde se desenvolvem as práticas sociais e políticas do trabalho, do estudo, do lazer, entre outras. Essa dinâmica reúne "[...] um conjunto indissociável de que participam de um lado, certo arranjo de objetos geográficos, objetos naturais e objetos sociais, e, de outro, a vida que os preenche e os anima [...]" (SANTOS, 1983, p. 14). Nela, o movimento que caracteriza a vida em sociedade e o espaço como construção histórica evolui de forma contínua e contraditória.

Essa compreensão é imprescindível nas abordagens sobre Formação 134 Continuada de Professores. A escola pública, em particular, trabalha com pessoas originadas da seletividade de classe socioeconômica, gênero, etnia, profissão, que definem o status social e político. E a escola não é pensada em termos de diversidade, conjuntamente, pelos pais e pelos professores, estudantes e funcionários. Quem pensa e define o que deve ser e como realizar-se o trabalho na instituição são intelectuais orgânicos, burocratas, políticos, empresários que estão fora dela; encontram-se, portanto, distantes das aspirações de quem a compõe.

No âmbito dos poderes instituídos, muitas pessoas que sequer entendem de educação, de ensino ou de aprendizagem, são aquelas tomadoras de decisão. Em sua maioria, expressam os interesses da classe dominante, ficando a educação e o ensino, em grande medida, à mercê de suas propensões. $\bigcirc$ campo da educação que é sustentado pela ideologia do capital, as pessoas seguem uma direção política neoconservadora que legitima a ordem social vigente, predestinando a educação a ser uma mercadoria lucrativa. Ainda que haja conflitos e consensos, nele prevalece um projeto político e ideológico que se apropria da realidade de forma natural e acabada, e não por meio de rupturas vislumbrando mudanças ou transformações sociais. 
O filósofo Dermeval Saviani (2000) tem contribuído, substancialmente, com reflexões sobre educação e escola voltadas para a realidade brasileira, destacando-se a Pedagogia histórico-crítica. No prefácio à sétima edição desse livro, ele critica a mistificação ideológica da educação, que oferece respostas imediatas às mazelas sociais e ressalta que,

Ao contrário disso, faz-se necessário retomar o discurso crítico que se empenha em explicar as relações entre a educação e seus condicionamentos sociais, evidenciando a determinação recíproca entre a prática social e a educativa, entendida, ela própria, como uma modalidade específica da prática social. E é esta, sem dúvida, a marca distintiva da pedagogia histórico-crítica (SAVIANI, 2000, p. 17).

São, portanto, inquestionáveis a premência e a atualidade da discussão sobre a pedagogia histórico-crítica, que remonta a 1979, quando o Brasil estava sob o regime civil-militar, na transição para a democracia. Entendemos que, sendo a educação e o trabalho docente uma particularidade do trabalho em geral, o professor deve estar em permanente atenção aos apelos do exercício de sua profissão. Conforme Lessard e Tardif (201 1, p. 8), remontam aos anos de 1980 os estudos sobre o ambiente escolar envolvendo as atividades docentes e suas relações com os estudantes. $\bigcirc$ estudos que se contrapõem às abordagens anteriores, de caráter normativo ou experimentais, "[...] confinavam a análise do ensino a variáveis mensuradas em laboratório ou, ainda, a normas tiradas da pesquisa universitária [...]". $\bigcirc$ novo paradigma, que orienta a concepção de trabalho docente como interativo, é compatível com as mudanças na base técnica da produção e, consequentemente, nas relações de trabalho e com a reestruturação do papel do Estado.

Conforme Freitas (2012, p. 91), os estudos sobre formação de professores que traduzem a ênfase ao modelo de ajuste neoliberal indicam problemas como "[...] a perpetuação das desigualdades, do baixo rendimento dos alunos e a repetência e o abandono da escola, remetendo, assim, às críticas sobre as reformas do ensino". Na declaração de Manágua (Nicarágua), que resultou do seminário internacional: Rumo a um novo modelo para o desenvolvimento de políticas sociais para crianças e jovens com deficiência e suas famílias em 1993, os educadores apontavam o baixo investimento financeiro e as precárias condições do trabalho docente, como causas da má qualidade da 
educação. O texto do documento acenava políticas que contemplassem uma legislação específica sobre o problema - a defesa de determinados direitos, cooperação, desenvolvimento de sistemas de informação, pesquisas - entre outras iniciativas governamentais.

Na confluência de abordagens contraditórias, a formação dos professores se tornava estratégica para o capital e, por parte dos empresários, acentuam-se os interesses pela educação em todos os níveis e modalidades de ensino. Essas perspectivas são consolidadas no Plano Compromisso Todos pela Educação, em 2007.

Historicamente desenvolvido como objeto de ações governamentais, o trabalho docente recebe atenção na forma de projetos específicos, que se concretizavam sob denominações distintas, a saber: treinamento, qualificação, capacitação, atualização. Mas foi, na década de 1990, que a categoria formação continuada ganhou o status de política nacional de educação, plena de tensões e, demarcada, dessa forma, por projetos políticos e pedagógicos antagônicos.

Queiroz e Garcia (2012, p. 182), em artigo sobre Planejamento e relações de poder, reforçam essa ideia, destacando que as políticas educacionais brasileiras, em particular nas duas últimas décadas têm sido movidas por forças sociais sistêmicas e contraditórias, que resultam de "[...] articulações entre instâncias de poder transnacional, nacional e local, de modo que um projeto de educação transnacionalizado apresenta antagonismos, confluências e embates analisados, particularmente, em nível escolar". Significa, pois, que o contraponto político e ideológico se mantém entre a perspectiva histórico-critica da pedagogia e o neoconservadorismo que nega a identidade e legitima diversas formas de repressão, com a "[...] criminalização dos movimentos sociais, da pobreza e da militarização da vida cotidiana" (BARROSO, 2000, p. 2091.

Com essa compreensão de sociedade brasileira, em particular, de educação, de escola e de ensino, situamos o professor como educador atuante, de modo especial no espaço escolar - na condição de sujeito do processo de ensino e aprendizagem. Lassard e Tardif (201 1, p. 7) mostram que a instrução, ao longo de, aproximadamente, quatro séculos é considerada uma atividade inerente ao mundo social. Assim, o ensino escolar, ou a escolarização - termo atualizado -, indistintamente, quanto à forma ou ao grau, tem "[...] 
proeminência sobre outras esferas de ação, [... ]", de modo que o exercício de qualquer profissão prescinde de ferramentas procedentes da instrução, da educação, do ensino ou da formação, em cuja base está o conhecimento como produção histórica.

Entendido dessa maneira, o conhecimento assume conotações diversas e, conforme Bertrand Roussell, pode ser considerado 'inútil', quando as pessoas ocupam todo o seu tempo com determinadas ciências úteis para ganhar a vida. Nessa reflexão, conclui o filósofo, em texto de 1935: "Em toda parte, o conhecimento vai deixando de ser visto como um bem em si mesmo ou como um meio de criar-se uma perspectiva de vida humana e abrangente e se transforma em mero ingrediente da aptidão técnica" (ROUSSELL, 2002, p. 39). $\bigcirc$ embate que permeia a educação escolar requer que seja recuperada uma concepção de conhecimento que inspire a compreensão da vida humana com possibilidades de transformação da realidade.

Nesse movimento, inscrevemos o trabalho docente no âmago do processo de escolarização "[...] como uma forma particular de trabalho sobre o humano, ou seja, uma atividade em que o trabalhador se dedica ao seu 'objeto' [sujeito] de trabalho, que é justamente outro ser humano, no modo fundamental da interação humana" (LASSARD; TARDIF, 2011 , p. 8). Aqui, o professor é visto em sua existência concreta, real, diante de uma realidade complexa, multifacetada, plena de incertezas. $\bigcirc$ cenário the atribui múltiplas funções e responsabilidades, que se modificam ao longo da história, sendo primordial a de educar e ensinar a crianças e jovens.

Estudo realizado por Queiroz (1984) constatou que, nos anos de 1980, os professores em escolas do meio rural no município de Ceará-Mirim, Rio Grande do Norte, além das atribuições pedagógicas, cuidavam, indistintamente, da gestão da escola e de todos os detalhes relativos à merenda até que ela fosse servida aos estudantes. Atualizando essa discussão, Oliveira (2006, p. 30) considera que, com a promulgação da Lei n 9.394, de 20 de dezembro de 1996, com as distintas orientações dos organismos multilaterais para as políticas de educação brasileira que a seguiram, novas exigências se impõem ao trabalho docente: "Esse quadro tem resultado em significativa intensificação do trabalho e precarização das relações de emprego, em mudanças que repercutem sobre a identidade e profissão docente". 
Ademais, as políticas de formação continuada de professores no Brasil, incentivadas a partir da década de 1990, decorrem, sobretudo, da necessidade de se redefinirem os processos de escolarização da educação básica no contexto internacional. Têm, como referência, as novas habilidades e competências requeridas do trabalhador, as quais vêm à tona com as mudanças no modo de produção capitalista e, em consequência, dos acordos firmados pelos países ocidentais com vistas ao alcance de determinadas metas na escolarização nesses países.

Nessa acepção, a agenda política dos governos brasileiros, a partir de 2003, priorizou, no planejamento, o Plano Plurianual e o Plano de Desenvolvimento da Educação (PDE). $\bigcirc$ plano, entre seus princípios, conjuga, por meio do contrato de gestão, os esforços da União, dos estados, do Distrito Federal e Municípios, tendo como norte o regime de colaboração visando à melhoria da qualidade da educação, medida pelo Índice de Desenvolvimento da Educação Básica (ldeb). $\bigcirc$ mecanismo de avaliação baliza a concepção de qualidade, direcionada para o alcance de habilidades em leitura, escrita e matemática no ensino fundamental.

O Plano de Metas Compromisso Todos pela Educação - Decreto $n^{\circ}$ 138 6.094, de 24 de abril de 2007 -, expressa o caráter de coalisão de forças com matizes ideológicos distintos na composição dos governos de 2003 a 2016. A composição política nos governos que compreende o período atraiu segmentos importantes do empresariado como definidores das políticas de educação, prevalecendo, o atendimento aos ditames do capital. $\bigcirc$ plano requeria "[...] a participação das famílias e da comunidade, mediante programas e ações de assistência técnica e financeira, visando à mobilização social pela melhoria da qualidade da educação básica" (BRASIL, 2007, p. 1).

Nos anos seguintes, o planejamento se estendeu, com ações específicas, aos municípios, por meio do Plano de Ações Articuladas. $\bigcirc$ plano, se situa como mecanismo na indução de políticas educacionais, em prosseguimento ao Plano de Desenvolvimento da Educação (PDE) e ao Plano de Metas Compromisso Todos pela Educação (Decreto n 6.094, de 24 de abril de 2007). Todos os planos visavam ao desenvolvimento de ações para estabelecer padrões de qualidade na educação brasileira, sendo pautados pelo alcance de previamente definidas. Em vista disso, foram concebidos agregando e construindo estratégias de ação que, pretensamente, contribuíssem para a melhoria da qualidade da educação nos estados e municípios 
brasileiros. Incluíam dimensões a serem priorizadas: gestão educacional, formação de professores, prática pedagógica e avaliação, infraestrutura física e recursos pedagógicos.

A análise dos dados da investigação realizada sobre a implementação do Plano de Ações Articuladas em uma amostra formada por duas capitais e mais oito municípios, de dois estados brasileiros, mostrou algumas tendências quanto às relações intergovernamentais nas ações de formação continuada.

\section{Tendências de relações intergovernamentais nas ações de formação continuada no PAR em municípios do Rio Grande do Norte e do Pará}

De posse dos dados colhidos no transcurso da pesquisa, entre os quais os das entrevistas com membros das secretarias municipais de educação (SMEC), em municípios da amostra, e seguindo a metodologia do WordSmith Tools, construímos o Word list, com um corpus de mil palavras, o concord. Os sujeitos estão identificados pela sigla do estado e do município; por ordem dos entrevistados e a pergunta. Tomamos as categorias de análise eleitas pelos pesquisadores, inerentes às relações intergovernamentais - regime de colaboração, participação, parceria e autonomia -, para identificar as tendências nas ações de formação continuada no Plano de Ações Articuladas 2007-20 11.

Além de parte do material das entrevistas, as análises cotejaram dados estatísticos e em documentos, os descritores dos conceitos fundantes, o aporte legal, normativo, e a literatura inerente a vários temas suscitados pela pesquisa. Na análise dos dados - interpretação e compreensão - da realidade específica dos municípios da amostra, identificam-se alguns limites inerentes ao corpus, que não puderam ser superados. A opção teórica e metodológica da investigação não induz a generalizações tampouco a conclusões definitivas.

Alguns conceitos presidiram as análises, entre os quais, o de regime de colaboração, prescrito na Constituição Federal Brasileira de 1988, que é reiterado pela Emenda Constitucional n 59, de 11 de novembro de 2009, e no qual se inscreve a educação "[...] dentro de um Sistema Nacional de Educação e expresso em um Plano Nacional de Educação" (CURY, 2012, p. 31 ). Sendo o regime conduzido pelo princípio da articulação recíproca - política e administrativa -, as relações entre os entes federados - União, estados, 
Distrito Federal e municípios - devem atender ao dispositivo constitucional segundo o qual a educação é considerada um direito de todos e dever do Estado (CORRÊA, 2006). Igualmente, o art. 10 da Lei de Diretrizes e Bases da Educação Nacional, de 20 de dezembro de 1996, inciso III "[...] estimula a integração entre as ações relativas a diretrizes e planos estaduais de Educação e as iniciativas dos municípios" (BRASIL, 1996, p. 17).

As bases do regime de colaboração no federalismo brasileiro, quanto à formação de professores, encontram-se no

Art. $4^{\circ}$ do Decreto nº 6.755/2009, que instituiu a Política Nacional de Formação de Professores da Educação Básica, destacando-se que o regime de colaboração deve processar-se na articulação dos entes federados por meio da criação de Fóruns Estaduais Permanentes e de ações e programas específicos do MEC (BRASIL, 2009).

Foi nessa conjuntura que se consolidou o Plano de Ações Articuladas, nos estados, nos municípios e no Distrito Federal, por meio da assinatura de um termo de adesão.

No processo de investigação, foram direcionadas algumas questões aos sujeitos pertinentes às ações dos municípios na dimensão Formação Continuada de Professores, contemplando as categorias eleitas. Seguindo-se um roteiro, indagava-se sobre a existência, a forma de definição e o financiamento dos cursos; a participação dos professores em eventos além daqueles promovidos pelo município; a existência e o uso de laboratórios, recursos e materiais audiovisuais e multifuncionais como estratégia de formação.

Entre os traços relevantes da amostra no Rio Grande Norte, o regime de colaboração foi identificado em ações dos programas de formação de professores financiadas pelo Ministério de Educação, de modo particular, com recursos procedentes do Fundo de Manutenção e Desenvolvimento da Educação Básica e de Valorização dos Profissionais da Educação (Fundeb) e do Plano de Ações Articuladas. Natal se destaca por haver uma política própria de formação continuada, para a qual se dispõe de um espaço físico construído com essa finalidade, o Centro Municipal de Referência em Educação Aluízio Alves (CEMURE). Nele, são realizadas algumas atividades com recursos financeiros próprios, e, para outras, conta com contrapartida financeira e 
técnica do Ministério da Educação e do Fundo Nacional de Desenvolvimento da Educação, contemplando coordenadores pedagógicos e professores.

Conforme um dos sujeitos da pesquisa, no espaço do

[... CEMURE - Centro de Formação -, todas as escolas receberam o material, como também os professores recebiam oportunidades de fazer cursos para usar a Plataforma, aprender a lidar com a tecnologia. $\bigcirc$ PROINFO foi um dos instrumentos muito utilizados pela Secretaria para que os professores tivessem acesso às tecnologias, [...] no contraturno (RN_MO1_INFO3_P54, 2015).

Também, no Centro de Formação, funcionam o laboratório de informática e as salas multifuncionais. Não obtivemos informações precisas sobre se havia formação específica para o pessoal que atuava no ambiente pedagógico. Um entrevistado disse que, com o lançamento do PROINFO e das salas multifuncionais, "Havia uma formação. [E acrescentou] não lembro, se estava incluída no PAR, mas já havia um acompanhamento anteriormente" (RN_MO INFO4_P54, 2015).

Ao longo de uma década, Mossoró aderiu aos programas do Ministério de Educação. A formação continuada concretizava-se por meio de cursos anuais e seminários de educação para a diversidade. A contrapartida da prefeitura consistia em destinar recursos para "[...] comprar alimentação, café, água, entendeu? e o pagamento do formador [...]" (RN_MO2_INFO3_ P50, 2015).

No município de Riachuelo, a formação de professores realizava-se na forma de semanas pedagógicas, com o Programa Gestão da Aprendizagem Escolar (Gestar) - I e II - e com o Programa Escola Ativa, com a oferta restrita de cursos inscritos no Programa Nacional de Tecnologia Educacional (Proinfo), Atendimento Educacional Especializado (AEE) e o Pro-Infantil. Quando a demanda para a formação excedia o número de vagas, fazia-se um sorteio entre os pretendentes (RN_MO3_INFO2_P53, 2015).

São José de Campestre, tal como os demais municípios, realizava mais de uma vez ao ano, quando chegavam os recursos (RN_MO5_INFO4_ P52, 2015) -, ações do programa Gestar para professores de português e matemática dos anos finais, do Pró-letramento e do Escola Ativa (RN_MO5_ INF04_P49, 2015). Todos recebiam assistência técnica do Fundo Nacional do Desenvolvimento da Educação (FNDE) e o apoio da Secretaria Estadual de 
Formação continuada de professores no PAR em municípios do Rio Grande do Norte e Pará

Educação do Rio Grande do Norte. O processo de formação contava com um tutor credenciado como multiplicador, para atuar nos momentos de capacitação. Geralmente, era contratada uma empresa para realizar os cursos.

Salientamos que não foi devidamente esclarecida a dúvida sobre se os recursos das ações de formação continuada se originavam do Plano de Ações Articuladas ou se elas se realizavam com a contrapartida da prefeitura. Um sujeito da pesquisa, referindo-se ao problema, afirma: "[...] eu sei que vinha dinheiro e, às vezes, eles pagavam e às vezes ficava e eles dividiam e ainda dava-se tipo uma bolsinha de cem reais [...] para os professores" (RN_MO5_INFO2_51, 2015).

Parte das ações de formação continuada para os professores dessa rede de ensino era promovida na modalidade a distância, conforme

[... critérios de quem podia e quem não podia ingressar [...] a exemplo de quem possuía o curso superior. [A] maioria que fez especialização foi particular, eles mesmos adquiriram com recursos próprios. Eu não me lembro de mais quais foram os cursos feitos; eu sei que eu me lembro bem da Plataforma Freire, dos cursos de capacitação oferecidos pela secretaria do estado [...] (RN_MO5_ INF03_P50, 2015).

Considerando as evidências acerca das ações de formação continuada como dimensão do Plano de Ações Articuladas 2007-20 11 apresentadas nos municípios da amostra no Rio Grande do Norte, com exceção de Acari, a tendência era uma efetivação relativa do regime de colaboração dos entes federados (ABRÚCIO, 2005). As decisões, no entanto, emanavam e retornavam à União.

No estado do Pará, a pesquisa foi desenvolvida em cinco municípios: Altamira, Barcarena, Belém, Cametá e Castanhal. O regime de colaboração, evidenciou-se, a partir das informações advindas dos entrevistados, que alguns municípios apresentavam iniciativas voltadas para a formação continuada de professores antes da adesão ao PAR em 2007.

Em Belém, conforme o diagnóstico e o relatório do PAR, de forma geral a área Formação Continuada apresentou uma situação satisfatória, indicando que o município já desenvolvia ações com essa finalidade. Em Barcarena, os informantes disseram que a oferta de cursos de formação continuada consistia em uma iniciativa da própria Secretaria Municipal de Educação e, com o 
Plano de Ações Articuladas, firmou-se a parceria com o MEC: "[...] sempre também a Secretaria estava investindo em formação continuada, trazendo universidades pra cá, trazendo cursos de aperfeiçoamento. Inclusive pelo próprio Plano de Ações Articuladas, vários técnicos, vários professores fizeram também formação continuada [...]" (PA_MO2_INF3_P49, 2015). Entre os cursos ofertados pelo MEC, um dos entrevistados ressaltou: "A gente tem de formação continuada que é o PACTO: o professor recebe uma bolsa mensal de 200 reais, e o professor orientador 750 [...]" (PA_M02_INF2_P51, 2015).

No município de Castanhal, também se realizava a formação como iniciativa de política interna da SEMED, conforme relata um dos informantes: "O município realizou diversas ações, mas que não estavam diretamente ligadas ao PAR" (PA_MO5_INF1_R49, 2015). Outras iniciativas decorreram de demandas relacionadas ao Plano de Ações Articuladas: "Das formações continuadas que têm ligação com o PAR, nós já tivemos proposta para o Pró-conselho, Alfabetização na Idade Certa pelo PACTO, saem todas pelo SIMEC via PAR. [...]" (PA_M05_INF1_P49, 2015).

Em Altamira, as ações geradas para a formação continuada resultaram de parceria firmada entre a Secretaria Municipal de Educação e o MEC. Foram geradas ações nas quais se destacavam programas com foco no ensino e na aprendizagem em língua portuguesa e em matemática, como Próletramento, Gestar e Escola Ativa.

Da mesma forma, em Cametá, as iniciativas se deram por meio dos programas federais - Gestar e Pró-Letramento -, segundo informou um entrevistado: "As ações eram através de programas, por exemplo, de pró-letramento. Não eram iniciativas do poder público municipal já que eram programas que a SEMED aderia" (PA_MO4_INF1_P50, 2015).

Entendemos que a formação continuada é um processo contínuo, participativo e que deve desenvolver-se de forma contextualizada. É, portanto, sua contribuição significativa para a melhoria da educação pública. A concepção e os procedimentos que a conduzem não devem levar a práticas reducionistas nem homogeneizantes, mas àquelas que atendam à diversidade cultural e pedagógica. A formação da qual participaram os professores das redes de ensino dos municípios da amostra da pesquisa está filiada diretamente aos programas de formação definidos no âmbito do Ministério de Educação com objetivos pontuais. 
Eles trazem, em sua matriz, algumas limitações e nem sempre, conseguem ater-se aos problemas concretos identificados no trabalho docente. Em consequência dos desacertos e diante do caráter histórico das políticas educacionais reformistas, às quais o PAR não foge, tem-se a culpabilização dos professores que são considerados como incompetentes e ineficientes. Sua formação torna-se para os gestores públicos, a causa do fracasso escolar e a resposta a ele.

Souza (2006), analisando essa perspectiva perversa, mostra a necessidade de se ter políticas educacionais abrangentes, que não apenas visem a uma formação continuada para desenvolver competências nos professores, mas, sobretudo, que se estendam à qualidade de todo o processo educativo. Isso porque a lógica da competência relaciona-se ao ideário da formação alicerçada na operacionalidade e na produtividade, traços que se imprimem à educação nos marcos da reforma do Estado neoliberal.

Entendemos que, na relação dos entes federados considerando-se a base legal e teórica acerca do regime de colaboração, prevalecem, na tomada de decisões, a concepção e as práticas de gestão verticalizadas. Vem dos entrevistados a informação de que "As ações eram através de programas

$144[\ldots]$ Não eram iniciativas do poder público municipal, já que eram programas que a SEMED aderia" (PA_MO5_INF1_P49, 2015). "São critérios estabelecidos pelo governo federal" (PA_M05_INF1_P50, 2015). Ressaltamos, ainda, que a centralidade do projeto de formação continuada, por meio dos programas originários do MEC, na melhoria do ensino e da aprendizagem da língua portuguesa e matemática, encaminha para resultados voltados, diretamente, para a elevação dos Índices de Desenvolvimento da Educação Básica (ldeb), sobre os quais pesam severas críticas.

Detendo-nos no regime de colaboração, entendemos, conforme Ghanem Júnior (2010), que o princípio da participação e sua pertinência em educação acenam como susceptíveis à organização da sociedade, que exerce pressão sobre os dirigentes do Estado brasileiro, em todas as instâncias da Federação. De igual modo, os esforços para promovê-lo assumem conotações distintas, transitando, inclusive,

[...] na forma de lobbies, alguns de grande eficiência - apesar de as conquistas serem desconhecidas da opinião pública -, ocorrem principalmente na modificação de dispositivos legais e são 
instáveis por estarem sempre ameaçadas de não serem cumpridas pelo Poder Executivo (GHANEM JÚNIOR, 2010, p. 193).

plano como estratégia política na conjuntura da primeira década do terceiro milênio, pode ser considerado um convite à participação dos estados, do Distrito federal e dos municípios para se tornar, como membros da Federação brasileira, protagonistas nas políticas de educação para o ensino fundamental. Porém, condicionados à adesão a uma proposta do Ministério de Educação que abarcava demandas distintas, antes não contempladas com o caráter supostamente inclusivo.

Em Natal, a pesquisa do OBEDUC mostrou que o Plano Municipal de Educação 2005-20 14 - Lei municipal n 5.650, de 20 de maio de 2005, art. $2^{\circ}$ - atendia ao princípio da participação, referindo-se à sociedade civil nas avaliações periódicas de implementação. Nele, também é abraçada a formação continuada como política alinhada aos programas e projetos do Ministério da Educação (MEC), como o Plano de Ações Articuladas 2007-20 11 .

Analisando a minuta do Plano de Ações Articuladas de Mossoró, nos dados relativos ao diagnóstico da educação, constatamos que, em 2006, o município havia aplicado um total de recursos originados da cota municipal do salário educação no valor de $R$ \$ 648.570,99 (seiscentos e quarenta e oito mil e quinhentos e setenta reais e noventa e nove centavos). $\bigcirc$ município desenvolvia ações específicas de formação continuada de professores, cuja participação era dessa forma evidenciada:

Geralmente, os planos, os orçamentos da prefeitura, [tinham] um recurso destinado à formação continuada. [Para] comprar alimentação, café, água e ao pagamento do formador. [Quanto aos formadores] Ou ele saía de sala de aula ou [ficava] só naquele curso. Por exemplo, como é Natal, você tem a carga horária, então você não fica pra aqueles cursos (RN_MO2_INFO3_P50, 2015).

No município de Riachuelo, a formação era incentivada pelo Programa Escola Ativa, cuja metodologia subsidiava um formador para multiplicá-la junto aos demais professores. Nessa formação, os docentes eram liberados no contraturno (RN_M04_INFO3_P49, 2015).

São José de Campestre apresentava-se com a particularidade de realizar as ações de formação continuada, porém, quando os recursos chegavam 
do Ministério de Educação. "Então, geralmente, o município contratava uma empresa [...]" (RN_M05_INF04_P49, 2015).

No estado do Pará, os informantes dos municípios da amostra revelaram que, no processo de elaboração, implementação e avaliação das ações do Plano de Ações Articuladas, não houve participação ativa dos sujeitos nesse nível da Federação. Um dos entrevistados do município de Altamira revelou que havia a tentativa de participação direta dos professores na escolha de cursos de especialização, mas esta fora frustrada:

[...] tivemos alguns cadastros via SIMEC em que foram oferecidas especializações para os professores, os professores se cadastraram na plataforma, logo em seguida teria um fórum estadual de educação pra que este fórum fosse selecionar os cursos mais solicitados pelos municípios, e infelizmente isso não aconteceu. Ficaram listados, os professores estão até hoje e continuam cadastrados no sistema, sem as devidas qualificações que eles solicitaram no momento, e parou. Estão lá. Muitos professores estão deixando de ser 'graduados' numa especialização, numa pós, por falta de um momento burocrático, de seleção ou problemas que politicamente poderiam ser, é, poderão solucionar a vida desse professor com especialização numa área que ele pudesse atuar em sala de aula (PA_MO1_INFO12_P53, 2015).

Em face do caráter com que se apresentam as políticas de formação continuada, a participação e as necessidades formativas dos professores são forjadas externamente, podendo-se afirmar, grosso modo, o desconhecimento dos anseios e de realidades específicas da educação pública brasileira. Esta carece de programas e projetos que contemplem a totalidade da dinâmica da escola como espaço educativo produzido com qualidade socialmente referenciada.

Algumas falas, a seguir, revelam o distanciamento dos sujeitos, em nível local, da Federação nas decisões acerca da implementação de políticas focalizadas: "As ações eram através de programas, por exemplo, de Pró-letramento. Não eram iniciativas do poder publico municipal já que eram programas que a SEMED aderia" (PA_MO4_INF 1_P50, 2015). E "São critérios estabelecidos pelo governo federal" (PA_M05_INF1_P50, 2015$).$

Sob esse ponto de vista, analisando-se o princípio de participação nas ações de formação continuada nos municípios da amostra no Pará, 
ressaltamos que prevaleciam as estratégias das políticas verticalizadas, e os dados coletados indicam, como tendência, que as decisões tomadas sobre - Plano de Ações Articuladas, ocorriam em nível macro, pela União como provedora e reguladora do financiamento para a educação (FARENZENA; MARCHAND, 2013).

Em se tratando da participação dos professores e da intensificação do trabalho docente, com exceção de Belém, onde se dispunha de horas de trabalho para o planejamento e a participação nas atividades, como é destacado a seguir "Nós temos uma coisa muito interessante na SEMEC, que é a HP, ela foi realmente institucionalizada [...]" (PA_M03_INF5_P49, 2015). Nos demais, municípios o trabalho do professor é intensificado sobremaneira, pois "A proposta é aos sábados, que a equipe trabalhe aos sábados [...] se a gente pega assim sexta feira, já nosso calendário tá muito apertado [...]" (PA_ MO2_INF2_P51, 2015); [...] como eram professores específicos da sala da aula, o município liberava naquele período, mas as aulas eram repostas aos sábados, que nós chamávamos de sábados de reposição (PA_MO I_INFO 12 P49, 2015).

A literatura mostra que a intensificação do trabalho docente, conforme é aqui abordado, compromete a qualidade de vida dos profissionais do magistério. Acarreta o adoecimento, entre outros problemas, expondo, ainda mais, a qualidade do processo de ensino e aprendizagem.

Conforme Farenzena (2009), a parceria, é outra particularidade da análise eleita neste texto, com o PDE associado ao Plano de Metas Todos pela Educação, constituiu-se em política, segundo a qual

MEC planejou um modo de apoiar os municípios com intermediação, propôs parcerias com Universidades, Instituições, UNDIME, Cefetes que pudessem fazer a mediação na implantação da política (FARENZENA, 2009, p. 11).

Seguindo essa orientação, o município de Natal firmou um convênio com a Universidade Federal do Rio Grande do Norte, por força do qual repassava os recursos financeiros a ele correspondentes. A universidade realizava os cursos de formação continuada de professores e certificava os concluintes (RN_MO1_INFO2_P51, 2015). 
Em Mossoró, o município dispõe de um Núcleo de Tecnologia Educacional (NTE), criado, em 2008, e reconhecido pelo MEC/PROINFO com o objetivo de

[...] atender às escolas municipais, por meio da adesão ao Programa Nacional de Tecnologia Educacional. Possui, além de computadores, retroprojetor, multimídia e outras tecnologias. $\bigcirc$ programa disponibiliza cursos de formação para os professores e conteúdos digitais, que possibilitam a dinamização das aulas, motivando os alunos na construção de sua aprendizagem e para o exercício da cidadania (MOSSORÓ, s/d).

No núcleo as atividades do Proinfo e "[...] a formação continuada é muito ativa. Existem também alguns cursos que são através do MEC; [...] a certificação vem pra cá, pra gente fazer o registro" (RN_MO2_INFO3_P54, 2015). As pessoas que atuam no núcleo dispõem de uma senha oficial de acesso às informações, para enviar relatórios e fazer outros registros dos cursos que nele estão sendo oferecidos.

Para desenvolver as ações de formação de professores, o município de Acari definiu parcerias com instituições privadas, como o Polo da Universidade do Vale do Acaraú (UVA) e o Instituto Superior (ISEP) para promover cursos de especialização, e com a Universidade Federal do Rio Grande do Norte (UFRN). As demandas procediam mais da educação infantil. "Quem mais tem resistência com relação à formação é o pessoal do $6^{\circ}$ ao $9^{\circ}$, de disciplinas específicas; são aqueles que geralmente eles sabem de tudo, são mais resistentes" (RN_M04_INF03_P53, 2015).

Nos municípios paraenses que fazem parte da amostra da pesquisa, segundo os informantes, as Secretarias Municipais de Educação firmaram parcerias com o MEC e com instituições locais públicas e privadas de ensino. No município de Altamira, a parceria se estabeleceu com o setor público e o privado:

Nós tivemos algumas especializações que foram pelo EDUCIMAT em parceria com a UFPA e o MEC, e Tecnologias em Educação em parceria com as secretarias de educação, como sempre, o MEC, a Universidade é a PUC (PA_MO1_INFO12_P53, 2015). 
As parcerias com universidades públicas e privadas, no percurso da formação continuada, também foram identificadas em Barcarena: "[...] sempre também a secretaria estava investindo em formação continuada, trazendo universidades pra cá, trazendo cursos de aperfeiçoamento [...]" (PA_MO2_ INF3_P49, 2015). Observa-se também parceria com instituição universitária na fala do informante PA_MO4_INF5_P52, do município de Cametá ao enunciar parceria com a UFPA, bem como Castanhal. "Por exemplo, o Pacto, tivemos o professor da UFPA pelo MEC que acompanhou as ações do Pacto no município" (PA_MO5_INF1_P52, 2015).

Ainda que uma das principais parcerias seja com instituições de educação superior, ressaltamos que, ao se contratarem universidades, sobretudo particulares ou empresas privadas para promover cursos de formação continuada para professores, intensificam-se os mecanismos mercadológicos que influenciam a concepção de gestão gerencial, centrada nas políticas de metas. Ao mesmo tempo, consolida-se a presença do setor privado na condução de programas educacionais nas redes públicas de ensino.

Compreendemos autonomia como uma faculdade segundo a qual "[...] os indivíduos ou organizações têm de se reger por regras próprias. Não obstante, a autonomia não se confunde com independência, sendo um conceito relacional, isto é, somos sempre autônomos em relação a alguma coisa" (BARROSO, 2000, p. 17). Corroborando essa análise sobre as relações intergovernamentais previstas no art. $1^{\circ}$ da Constituição da República Federativa do Brasil entre União, estados, municípios e o Distrito Federal, elas são indissociáveis e se efetivam sob a coordenação e o princípio da autonomia, pelo regime de colaboração e descentralização de poder.

Essa autonomia que regula as relações federativas entre as instâncias de governo não é sinônimo de soberania, visto que se efetiva mediante tensões entre competências privativas da União e competências comuns e concorrentes de todos os entes federados (DOURADO, 2013). Assim entendendo, a União é o ente responsável por estabelecer normas gerais, mas a efetivação dessas normas não deve implicar a perda de autonomia dos governos subnacionais, como expressa o $\S 2^{\circ}$ do art. 24 da CF de 1988: "A competência da União para legislar sobre as normas gerais não exclui a competência suplementar dos estados" (BRASIL, 1988). 
Os dados da pesquisa sobre a formação continuada de professores são reveladores de que, historicamente, o município de Natal tem uma política nessa dimensão para atender às modalidades, etapas de ensino e funções distintas: EJA, educação infantil, ensino fundamental e gestores escolares. Mantém uma sistemática, com calendário específico, segundo o qual "[... toda segunda e quarta-feira do mês tem um encontro com os gestores que é não só administrativo, de avisos, mas sempre tem um aspecto de formação nesses encontros" (RN_MO1_INFO3_P49, 2015).

As características dessa política indicavam que o ente federado tinha autonomia relativa, uma vez que parte das ações de formação emanavam do Ministério de Educação configurando, também, políticas induzidas, e a Secretaria Municipal de Educação exercia a função primordial de executá-las. Essa conduta política levava a Secretaria a divulgar e incentivar ações de formação continuada com frequência, ainda que nem sempre oferecesse incentivo financeiro. Além dessas particularidades na formação continuada, o município incentivava os professores a participar de eventos, e, em algumas situações, "[...] a Secretaria comprava uma quantidade de inscrições em alguns cursos e disponibilizava para as escolas. Não podia mandar pra todos,

150 mas disponibilizava para os técnicos da Secretaria" (RN_MO1_INFO3_P53, 2015). Dessas informações, podemos inferir que essa instituição não interferia diretamente nas decisões sobre quem iria participar dos eventos, revelando-se, pois, assimetria no princípio que orienta as relações interinstitucionais.

O município de Mossoró, em consonância com Natal mantinha autonomia política e pedagógica para realizar determinadas ações de formação continuada de professores, atendendo também às etapas e modalidades de ensino, destacando-se como evidência, o programa Gestar. "O Departamento de Gestão reunia os gestores às segundas e quarta-feiras do mês para cuidar de assuntos administrativos (avisos)". Por parte dos gestores, havia o entendimento de que a formação continuada não deveria ser uma obrigação exclusiva da Secretaria. Salientamos que a presidente da comissão de progressão funcional afirma que entre os requisitos "[...] tem um ponto que diz respeito à formação continuada. Eu vejo todos os processos; alguns, um percentual muito pouco, faz outros cursos, além dos que eram ou são oferecidos pela Secretaria municipal. A grande maioria, que não faz, só espera ou só faz os cursos oferecidos por aqui" (RN_MO1_INFO3_P49, 2015). 
Em Acari, a formação continuada de professores se restringia às modalidades educação especial e educação do campo, com cursos que atendiam a essas demandas. As inscrições se faziam no setor do PAR (RN_MO3_INFOI_ P53, 2015).

Nos municípios paraenses, detectamos que a autonomia era relativa, na relação entre os municípios e a União, pois a competência de cada ente federado era preconcebida pelo poder central e cada um recebia determinadas atividades para serem cumpridas. No processo de elaboração do Plano de Ações Articuladas, aos municípios competia assinar o termo de adesão, constituir um comitê local para fazer o preenchimento de formulários on-line cujas questões e respostas já estavam prontas e delimitadas conforme o entendimento dos planejadores em nível do governo central.

Dessa forma, os municípios não poderiam opinar sobre ou solicitar ações para além das listadas no sistema SIMEC, mesmo que estas estivessem em parte distanciadas da realidade educacional paraense. As ações geradas para a formação continuada de professores, assim como para as demais áreas e dimensões do plano, não passaram por uma consulta prévia aos principais interessados, que eram os professores das redes municipais de ensino. Os sujeitos eram selecionados e/ou convocados para participar de determinados cursos, cujos objetivos e estratégias não passaram por seu controle, nem mesmo pelo da escola onde eles atuavam ou da Secretaria Municipal de Educação à qual estavam vinculados.

As informações, advindas de sujeitos da pesquisa reiteram o que vimos abordando neste item do trabalho. No município de Altamira, os programas voltados para a formação continuada não foram planejados pelos técnicos da Secretaria Municipal de Educação e pelos professores da rede pública de ensino, mas encaminhados, pelo MEC como é dito a seguir:

Os professores de língua portuguesa e matemática tiveram formação através do programa Gestar por mais ou menos oito meses de programa e depois que terminou a secretaria continuou fazendo as formações. Nós tivemos o pró-letramento, do primeiro ao quinto ano [...] quando eu me referia à escola do campo, eu estava falando do programa Escola Ativa. [...] em relação à Escola Ativa e as escolas indígenas, eles também faziam parte dessa formação 'in loco'. [...] Em relação à educação especial, [existiam] as salas de AEE [...] através do programa Brasil Alfabetizado, as pessoas 
que saíam dali, eles iam para a primeira etapa da EJA (PA_MO I_ INFO12_P49, 2015).

Com base no exposto, percebemos que os programas referendados, supostamente, se propunham à suprir as necessidades dos professores, mas sem que estes tivessem autonomia para se posicionar ou reivindicar algo conforme os interesses das escolas onde exerciam a docência. Recebiam um pacote pronto para qualificá-los quanto ao ensino e à aprendizagem, especialmente em língua portuguesa e matemática.

Os demais municípios seguem como tendência prevalecer a ausência de autonomia para participar de discussões, debates e na tomada de decisões. Nessa perspectiva, informante de Barcarena afirma que o Plano de Ações Articuladas foi um importante mecanismo para planejar as ações educativas do município, mas pouca importância recebeu da comunidade escolar no acompanhamento e na avaliação das ações. Essas tarefas recaíram sobre - Comitê local, sobre os técnicos da Secretaria Municipal de Educação, como ele enfatiza: "[...] a gente faz a chamada para as outras entidades que vão consolidar o comitê. Vão nas primeiras reuniões, participam da elaboração; chega na hora de avaliar as ações somente os técnicos da secretaria" (PA_ MO2_INF3_P52, 20151.

A autonomia precisa ser construída de forma coletiva pelos sujeitos educacionais. Segundo Barroso (1996) "[...] esta autonomia construída corresponde ao jogo de dependências que os membros de uma organização estabelecem entre si e com o meio envolvente e que permitem estruturar a sua acção organizada em função de objectivos colectivos próprios" (BARROSO, 1996 , p. 10). Desse modo, as ações educacionais podem firmar-se como expressão da vontade e das decisões da unidade socialmente construída que é a escola.

TENDÊNCIAS NAS RELAÇÖES INTERGOVERNAMENTAIS EM MUNICÍPIOS DO RIO GRANDE DO NORTE E DO PARÁ

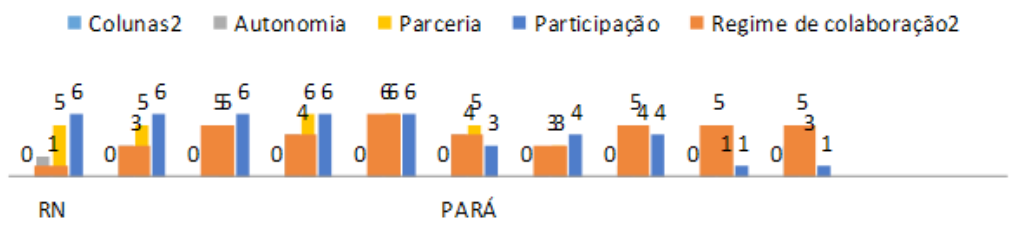

Fonte: Autores 
O gráfico, que mostra as tendências nas relações intergovernamentais em municípios do estado do Rio Grande do Norte e do Pará, bem explicita, entre outros aspectos, diferenças significativas na estrutura dos entes federados, em termos de política de Formação Continuada de Professores. Indica que, onde elas eram efetivas, reduziam-se as demandas ao plano, a começar pelo regime de colaboração dos entes federados. Conforme dados da pesquisa, nos municípios da amostra no Rio Grande do Norte, à exceção de Acari, é possível identificar-se alguns programas ou projetos induzidos pelo Ministério de Educação.

No estado do Pará, destacamos Altamira, onde a área 1- Formação Continuada de Professores - recebeu pontuação 1, pois estava em uma situação crítica e carente de ações. Também nos demais municípios, nos quais mesmo existindo ações criadas pela Secretaria Municipal de Educação, ainda eram insuficientes para atender à demanda.

Autonomia relativa foi identificada em Natal e em Mossoró, evidenciando que os municípios desenvolviam políticas efetivas de formação continuada. No segundo deles, no entanto, não foram geradas ações nessa categoria.

Nos Municípios paraenses, seguiu-se, também, essa tendência.

Belém, Barcarena e Castanhal apresentaram formação continuada por iniciativa da Secretaria e a complementaram com as ações do PAR. Em Cametá e Altamira, ficou demonstrado, que os programas existentes têm sua matriz no Plano de Ações Articuladas.

Não foi evidenciada participação direta da União nas ações de formação continuada em Acari e Riachuelo no Rio Grande do Norte. Os demais municípios se integravam aos programas financiados pelo FNDE/Ministério de Educação. Nas ações desenvolvidas pelo PAR, nos municípios paraenses, identifica-se, a participação direta do ente federado local.

Nos cinco municípios do Rio Grande do Norte, constatou-se parceria, sendo que, em Mossoró, havia contrapartida do ente federado local, que destinava recursos, no orçamento da prefeitura, para a formação continuada, com a finalidade de suprir o pagamento de gêneros alimentícios ao formador.

A parceria foi estabelecida pelas Secretarias Municipais de Educação paraenses, sobretudo, com instituições de educação superior públicas e/ ou privadas que assessoraram, tecnicamente, a execução dos programas federais. 
A despeito das evidências demonstradas com os dados da pesquisa, configurando, nas relações intergovernamentais, tendências de os demais entes federados se articularem com a União, por meio do regime de colaboração, com autonomia, participação e parceria de forma relativa, prevalecem, no entanto, as relações verticalizadas. As políticas são formuladas em nível central - no MEC - e retornam à União, sendo que os demais entes federados são induzidos a nelas se inscreverem, como foi com o Plano de Ações Articuladas, objeto dessa discussão.

\section{Considerações finais}

Os dados da pesquisa em municípios da amostra no Rio Grande do Norte e no Pará, que emanaram de fontes distintas, tornaram possível identificar opções que permeavam a política de planejamento da educação brasileira entre 2007 e 2011 , desenvolvida, estrategicamente, por meio de planos plurianuais. Eles revelam intenções e práticas de seus autores na definição de objetivos e metas a serem alcançados, de modo particular no Plano de Ações Articuladas, na dimensão Formação Continuada de Professores.

Sendo a escola o lugar do trabalho docente por excelência, ela contempla profissionais adultos - na condução dos processos de ensino e aprendizagem, junto a estudantes - jovens e crianças -, todos sujeitos da história, em seu desenvolvimento integral. Como parte do universo de relações similares, o professor só ingressa no magistério com formação inicial específica e, diante dos apelos da sociedade circundante, deve manter atualizados os conhecimentos atinentes ao exercício da docência por meio da formação continuada.

Essa tarefa, no sistema educacional brasileiro foi instituída pela Constituição Federal de 1988 e a Lei n 9.394, de 20 de dezembro de 1996, como responsabilidade do estado e da União, os principais provedores dos recursos que são transferidos aos demais entes federados, para concretização das políticas agendadas em determinados períodos.

A investigação realizada sobre a formação continuada de professores na implementação do Plano de Ações Articuladas acena que, nessa ocasião, alguns deles desenvolveram ações de formação continuada com relativa autonomia e envolvendo parceria, participação e regime de colaboração. Prevaleceu, no entanto, a tendência na qual as decisões políticas eram 
verticalizadas, iniciando-se nas instâncias centrais de poder - a União - e a ela retornando em forma de acompanhamento e controle. Os municípios, no entanto, visando à obtenção do financiamento à proposta de programas com a configuração do PAR.

aporte teórico e metodológico, apreendido em livros, periódicos, teses, dissertações, na legislação, em documentos e em parte das entrevistas, possibilitou agregar, no processo de análise, os dados originados dessas fontes. Por tratar-se de ações políticas no federalismo integrado pela União, estados, municípios e Distrito Federal, na amostra da pesquisa no Rio Grande do Norte constatou-se, ainda que, de forma tímida, em Natal e em Mossoró.

Neste último, apenas algumas ações foram geradas na formulação do Plano de Ações Articuladas. A ausência do atributo nos demais municípios indica que quanto menor ele é, mais restritas são as possibilidades de desenvolver políticas com recursos próprios, estando, pois, na maior dependência da União.

A pesquisa apontou que, no estado do Pará, na relação dos entes federados a gestão e o planejamento dos programas de formação continuada são conduzidos pelo governo federal visando ao alcance da eficiência e da eficácia da/na prática docente. Destaca-se a ênfase na leitura, na escrita e nos conhecimentos matemáticos para alcançar índices que expressem resultados quantitativos balizados nas avaliações em larga escala, que culminam no Ideb.

Quanto à parceria nas ações de formação continuada, o município de Natal firmou convênio com a Universidade Federal do Rio Grande do Norte para formar professores. Mossoró integrava vários programas induzidos pelo MEC e apresentava contrapartida com recursos originados do orçamento municipal em situações de formação continuada. São José de Campestre tinha plena dependência dos recursos do FNDE/Ministério de Educação. A parceria de Acari era diretamente com a União e com instituições de ensino superior públicas e privadas para realizar cursos lato sensu. As ações dessa dimensão em Riachuelo estavam relacionadas aos programas do MEC, inclusive o Plano de Ações Articuladas.

No estado do Pará, as parcerias também foram firmadas com instituições de ensino superior na concretização das políticas focais induzidas por governos, em distintos períodos, em âmbito federal. Essas políticas, 
desenvolvidas com caráter pontual, supostamente se voltam para o atendimento de necessidades emergenciais, mas, em sua essência, correspondem ao atendimento dos interesses dominantes por parte do Estado.

Nesse sentido, a política de Formação de Professores, no plano, tanto no Rio Grande do Norte quanto no Pará não contemplou, efetivamente, a participação das Secretarias Municipais de Educação na tomada das decisões. Ademais, em sua formulação, a realidade é abstraída, e, consequentemente, não fluem os problemas nem as realizações das escolas que poderiam expressar a qualidade social do processo de ensino e aprendizagem.

A análise dos dados obtidos nas fontes estudadas foi fundamental para compreender realidades específicas sob a mediação de conceitos como regime de colaboração, participação, parceria e autonomia, para iluminar, na implementação de ações do PAR, as tendências das relações intergovernamentais. Reforça, portanto, a compreensão de que uma política de educação focada em determinado objeto, e em sujeitos distintos, em um tempo limitado, não tem força suficiente para mudar a cultura que preside as relações intergovernamentais verticalizadas; ou seja, centrada na União, como reguladora e financiadora. Às demais instâncias, cabe executá-las com autonomia relativa.

\section{Referências}

ABRÚCIO, Fernando Luiz. A coordenação federativa no Brasil: a experiência do período FHC e os desafios do governo Lula. Revista Sociologia Política, Curitiba, n. 24, p. 41-67, jun. 2005.

BARROSO, João. O estudo da autonomia da escola: da autonomia decretada à autonomia construída. In: BARROSO, João (Org.). O Estudo da Escola. Porto: Porto Editora, 1996.

- reforço da autonomia nas escolas e a flexibilização da gestão escolar em Portugal. In: FERREIRA, Naura Syria Carapeto (Org.). Gestão democrática da educação: atual tendência, novos desafios. 2. ed. São Paulo: Cortez, 2000.

BRASIL. Constituição Federal de 1988. Promulgada em 5 de outubro de 1988. Diário Oficial [da] União, Poder Executivo, Brasília, DF, 5 out. 1988. Seção 1, p. 1.

Lei n 9.394 de 20 de dezembro de 1996. Estabelece as Diretrizes e Bases da Educação Nacional. Diário Oficial [da] União, Poder Executivo, Brasília, DF, 23 dez. 1996. Seção 1, p. 27833. 
Decreto $\mathbf{n}^{\circ} \mathbf{6 . 0 9 4}$, de 24 de abril de 2007. Dispõe sobre a implementação do Plano de Metas Compromisso Todos pela Educação. Disponível em: http:/ / www. planalto. gov.br/ccivil_03/_Ato2007-2010/2007/Decreto/D6094.htm. Acesso em: 31 maio 2017.

Decreto $\mathbf{n}^{\circ}$ 6.755, de 29 de janeiro de 2009. Institui a Política Nacional de Formação de Profissionais do Magistério da Educação Básica. Brasília: Casa Civil da Presidência da República, 2009.

CURY, Carlos Roberto Jamil. Lei de responsabilidade educacional. Direito e Sociedade, Catanduva, v. 7, p. 9-18, 2012.

DOURADO, Luiz Fernandes. Sistema nacional de educação, federalismos e os obstáculos ao direito à educação básica. Educação \& Sociedade, Campinas, v. 34, n. 124, p. 761 785, jul./set. 2013.

FARENZENA, Nalú. Políticas de assistência financeira na educação básica: ação redistributiva da União? Paris: IIPE, 2009.

FARENZENA, Nalú; MARCHAND, Patrícia Souza. Relações Intergovernamentais na educação à luz do conceito de regulação. Cadernos de Pesquisa, Campinas, v. 43, n. 150 p. 788-811, set./dez. 2013.

FREITAS, Alexandre Simões. Os desafios da formação de professores no século XXI: competências e solidariedade. In: FERREIRA, Andréa Tereza Brito (Org.). Formação continuada de professores. Belo Horizonte: Autêntica, 2012.

GHANEM JÚNIOR, Elie George Guimarães. Participação e regime de colaboração entre unidades federadas na educação brasileira. In: OLIVEIRA, Romualdo Portela de; SANTANA, Wagner (Org.). Educação e federalismo no Brasil: combater as desigualdades, garantir a diversidade. Brasília: Unesco, 2010.

LESSARD, Claude; TARDIF, Maurice. As transformações atuais do ensino: três cenários possíveis na evolução da profissão do professor? In: TARDIF, Maurice; LESSARD, Claude (Org.). O ofício do professor: história, perspectivas e desafios internacionais. Petrópolis: Vozes, 2011.

LIMA, Licínio Carlos. A escola como organização e a participação na organização escolar. Braga: Universidade do Minho, 2008.

MOSSORÓ. Histórico do Núcleo de Tecnologia Educacional Municipal. s/d. Disponível em: http://tecnologiasmossoro.blogspot.com.br/p/n.html. Acesso em: 13 fev. 2017. 
NATAL. Lei $\mathbf{n}^{\circ}$ 5.650, de 20 de maio de 2005. Aprova o Plano Municipal de Educação do Município de Natal e dá outras providências. Disponível em: https://cm-natal.jusbrasil. com. br/legislacao/243680/lei-5650-05. Acesso em: 30 maio 2017.

OLIVEIRA, Dalila Andrade. A reestruturação do trabalho docente: precarização e flexibilização. Educação \& Sociedade, Campinas, v. 25, n. 89, p. 11 27-1 144, set./dez. 2006.

PA_M01_INFO12_P49. Entrevista. Altamira (Pará), 14 set. 2015.

PA_MO1_INFO12_P53. Entrevista. Altamira (Pará), 14 set. 2015.

PA_M02_INF2_P5 1. Entrevista. Barcarena (Pará), 21 jul. 2015.

PA_M02_INF3_P49. Entrevista. Barcarena (Pará), 21 jul. 2015.

PA_M03_INF5_P49. Entrevista. Belém (Pará), 22 jun. 2015.

PA_M02_INF3_P52. Entrevista. Barcarena (Pará), 21 jul. 2015.

PA_MO4_INF1_P50. Entrevista. Cametá (Pará), 21 jul. 2015.

PA_M04_INF5_P52. Entrevista. Cametá (Pará), 21 jul. 2015.

PA_M05_INF1_R49. Entrevista. Castanhal (Pará), 10 set. 2015.

PA_M05_INF1_P50. Entrevista. Castanhal (Pará), 10 set. 2015.

158 PA_M05_INF1_P52. Entrevista. Castanhal (Pará), 10 set. 2015.

QUEIROZ, Maria Aparecida de. A questão rural e os desacertos da educação: o caso de Ceará-Mirim. Campinas, 1984. 157f. Dissertação (Mestrado em Educação) - Programa de Pós-Graduação em Educação, Universidade Estadual de Campinas, Campinas, 1984.

; GARCIA, Luciane Terra dos Santos. Planejamento e relações de poder: antagonismos na política educacional. Revista Educação em Questão, Natal, v. 43, n. 29, p. 182-207, maio/ago. 2012.

ROUSSELL, Bertrand. O ócio criativo. Rio de Janeiro: sextante, 2002.

RN_MO1_INFO2_P54. Entrevista. Natal (Rio Grande do Norte), 25 set. 2015.

RN_MO1_INFO3_P49. Entrevista. Natal (Rio Grande do Norte), 25 set. 2015.

RN_MO1_INFO3_P53. Entrevista. Natal (Rio Grande do Norte), 25 set. 2015.

RN_MO1_INFO3_P54. Entrevista. Natal (Rio Grande do Norte), 25 set. 2015.

RN_MO1_INFO4_P54. Entrevista. Natal (Rio Grande do Norte), 25 set. 2015.

RN_MO2_INF03_P50. Entrevista. Mossoró (Rio Grande do Norte), 25 set. 2015.

RN_M02_INFO3_P54. Entrevista. Mossoró (Rio Grande do Norte), 25 set. 2015. 
RN_M03_INFO1_P53. Entrevista. Riachuelo (Rio Grande do Norte), 25 set. 2015.

RN_M03_INFO2_P53. Entrevista. Riachuelo (Rio Grande do Norte), 25 set. 2015.

RN_M03_INFO1_P53. Entrevista. Riachuelo (Rio Grande do Norte), 25 set. 2015.

RN_M04_INF03_P49. Entrevista. Acari (Rio Grande do Norte), 25 set. 2015.

RN_M04_INF03_P53. Entrevista. Acari (Rio Grande do Norte), 25 set. 2015.

RN_M05_INFO2_51. Entrevista. São José de Campestre (Rio Grande do Norte), 25 set. 2015.

RN_M05_INF03_P50. Entrevista. São José de Campestre (Rio Grande do Norte), 25 set. 2015.

RN_M05_INF04_P49. Entrevista. São José de Campestre (Rio Grande do Norte), 25 set. 2015.

RN_M05_INF04_P52. Entrevista. São José de Campestre (Rio Grande do Norte), 25 set. 2015.

SANTOS, Milton. Posface: Les nouveaux mondes de la géographie. In: BAILLY, Antoine; FERRAS, Robert; PUMAIN, Denise (Org.). Encyclopédie de géographie. Paris: Economica, 1983.

SAVIANI, Dermeval. Escola e democracia: teorias da educação, curvatura da vara, onze teses sobre educação e política. São Paulo: Cortez, 1984.

Pedagogia histórico-crítica. Campinas: Autores Associados, 2000.

SOUZA, Denise Trento Rebello de. Formação continuada de professores e fracasso escolar: problematizando o argumento da competência. Educação e Pesquisa, São Paulo, v. 32, n. 3, p. 477-492, set./dez. 2006.

WERLE, Flávia Obino Corrêa. Contexto Histórico e Atual das Políticas Educativas: autonomia e regime de colaboração. In: WERLE, Flávia Obino Corrêa (Org.). Sistema municipal de ensino e regime de colaboração. Injuí: Editora Unijuí, 2006.

Profa. Dr ${ }^{a}$. Maria Aparecida de Queiroz Universidade Federal do Rio Grande do Norte Programa de Pós-graduação em Educação

Grupo de Pesquisa "Avaliação do Plano de Ações Articuladas (Par): um estudo em municípios dos estados do Rio Grande do Norte, Pará e Minas Gerais no período de 2007 a $2011^{\prime \prime}$

E-mail | cidinhaufrn@gmail.com 
Prof. Ms. Marcos Torres Carneiro Universidade Federal do Rio Grande do Norte

Departamento de Fundamentos e Políticas

Grupo de Pesquisa "Avaliação do Plano de Ações Articuladas (PAR): um estudo em municípios dos estados do Rio Grande do Norte, Pará e Minas Gerais no período de 2007 a $2011^{\prime \prime}$

E-mail | torriscarneiro@gmail.com

Prof ${ }^{a}$. Dr ${ }^{a}$. Maria Edilene Silva Ribeiro Universidade Federal do Pará Faculdade de Pedagogia Programa de Pós-Graduação em Educação

Grupo de Pesquisa "Avaliação do Plano de Ações Articuladas (PAR): um estudo em municípios dos estados do Rio Grande do Norte, Pará e Minas Gerais no período de 2007 a $2011^{\prime \prime}$

E-mail | mariaedileneribeiro@yahoo.com.br

Recebido 29 ago. 2017 Aceito 31 out. 2017 